\title{
Consumption of sugar-sweetened and artificially sweetened soft drinks and risk of obesity-related cancers
}

\author{
Allison M Hodge ${ }^{1,2, *}$, Julie K Bassett ${ }^{1}$, Roger L Milne ${ }^{1,2}$, Dallas R English ${ }^{1,2}$ and \\ Graham G Giles ${ }^{1,2}$ \\ ${ }^{1}$ Cancer Epidemiology Centre, Cancer Council Victoria, 615 St Kilda Road, Melbourne, VIC 3004, Australia: \\ ${ }^{2}$ Centre for Epidemiology and Biostatistics, The University of Melbourne, Melbourne, Victoria, Australia
}

Submitted 6 December 2016: Final revision received 25 July 2017: Accepted 10 August 2017: First published online 21 February 2018

\begin{abstract}
Objective: To test the hypothesis that more frequent consumption of sugarsweetened soft drinks would be associated with increased risk of obesity-related cancers. Associations for artificially sweetened soft drinks were assessed for comparison.

Design: Prospective cohort study with cancers identified by linkage to cancer registries. At baseline, participants completed a 121-item FFQ including separate questions about the number of times in the past year they had consumed sugarsweetened or artificially sweetened soft drinks. Anthropometric measurements, including waist circumference, were taken and questions about smoking, leisuretime physical activity and intake of alcoholic beverages were completed.

Setting: The Melbourne Collaborative Cohort Study (MCCS) is a prospective cohort study which recruited 41514 men and women aged 40-69 years between 1990 and 1994. A second wave of data collection occurred in 2003-2007.

Subjects: Data for 35593 participants who developed 3283 incident obesity-related cancers were included in the main analysis.

Results: Increasing frequency of consumption of both sugar-sweetened and artificially sweetened soft drinks was associated with greater waist circumference at baseline. For sugar-sweetened soft drinks, the hazard ratio (HR) for obesityrelated cancers increased as frequency of consumption increased (HR for consumption $>1 / \mathrm{d} v$. $<1 /$ month $=1 \cdot 18 ; 95 \%$ CI $0.97,1.45 ; P$-trend $=0.007)$. For artificially sweetened soft drinks, the HR for obesity-related cancers was not associated with consumption (HR for consumption $>1 / \mathrm{d} v .<1 /$ month $=1 \cdot 00 ; 95 \%$ CI $0 \cdot 79,1 \cdot 27 ; P$-trend $=0 \cdot 61$ ).

Conclusions: Our results add to the justification to minimise intake of sugarsweetened soft drinks.
\end{abstract}

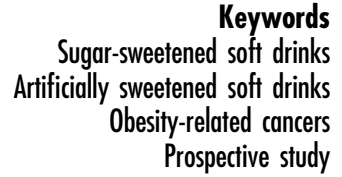

$\begin{aligned} & \text { Keywords } \\ & \text { Sugar-sweetened soft drinks }\end{aligned}$ sweetened soft drinks Prospective study
The Australian Health Survey 2011-12 $2^{(1)}$ found that 29\% of the population consumed soft drinks (including flavoured mineral waters) in the previous $24 \mathrm{~h}$. For 14- to 18-year-olds, $51 \%$ of males and $38 \%$ of females had consumed a soft drink the previous day. Thirty-two per cent of soft drink consumed was artificially sweetened and for those who reported soft drink consumption the median amount consumed was $375 \mathrm{ml} / \mathrm{d}$, equivalent to a regular size can.

One of the main areas of concern regarding sugarsweetened beverage consumption is the possible contribution to excess energy intake and the development of obesity, as reviewed recently regarding soft drinks, fruit drinks, iced teas, and energy and vitamin waters by Malik et $a l .{ }^{(2)}$. Other reviews have drawn inconsistent conclusions, but it has also been found that reviews funded by industry were less likely than other reviews to conclude there was a strong association between soft drink consumption and obesity ${ }^{(3)}$. A recent Australian study modelling the probable impact on obesity and health of a $20 \%$ tax on sugar-sweetened beverages estimated that the tax would decrease average consumption from 141 to $124 \mathrm{~g} / \mathrm{d}$ for men and from 76 to $67 \mathrm{~g} / \mathrm{d}$ for women, resulting in reductions of 16 and $9 \mathrm{~kJ} / \mathrm{d}$, respectively, and an average eventual weight loss of 320 and $170 \mathrm{~g}$ for adult males and females, respectively. This was calculated to translate into an additional 170000 healthy life-years over the lifetime of the adult Australian population in $2010^{(4)}$, based on the associations of obesity with nine conditions including colorectal, breast, endometrial and kidney cancer. 
Cancer Council Victoria has joined with thirteen health and community organisations in Australia to highlight to the public the amount of sugar in sweetened beverages and encourage Australians to rethink their consumption, but to date there is little evidence on whether the consumption of sugar-sweetened beverages is associated with cancer risk. A recent meta-analysis found no association between consumption of sweetened carbonated beverages and the risk of cancer overall or cancers of specific organs, but that study did not differentiate between sugarsweetened and artificially sweetened soft drinks or deal consistently with measures of body size. The authors also noted the poor quality of the studies analysed and that sweetened carbonated beverages and the risk of cancer was not their primary hypothesis ${ }^{(5)}$.

The World Cancer Research Fund currently identifies eleven cancers - i.e. liver, advanced prostate, ovary, gallbladder, kidney, colorectum, oesophagus (adenocarcinoma), postmenopausal breast, pancreas, endometrium and stomach (cardia) - as being linked to overweight and obesity ${ }^{(6)}$, hence we hypothesise that sugar-sweetened soft drink consumption would be associated with the risk of these cancers. Soft drinks, particularly colas, also contain 4-methylimidazole, a caramel colouring agent, which has been assessed as possibly carcinogenic in $\operatorname{man}^{(7)}$ and is found at similar levels in both artificially sweetened (diet) and regular soft drinks ${ }^{(8)}$. If this were an important mediator of associations between sugar-sweetened soft drinks and cancers, it would be expected that a similar association would be seen for diet soft drinks. Our aim, therefore, was to investigate prospectively the association between sugar-sweetened soft drinks and obesity-related cancer, using data from the Melbourne Collaborative Cohort Study (MCCS). The association for artificially sweetened soft drinks was also assessed for comparison. Further investigation into the risk of obesity-related cancers following changes in soft drink consumption between baseline and follow-up (median time between surveys was 11.6 years) was also conducted.

\section{Methods}

\section{Study sample}

The MCCS is a prospective cohort study which recruited 41514 men and women aged 40-69 years between 1990 and $1994^{(9)}$. All participants not known to have died were invited to a second wave of data collection that occurred from 2003 to 2007. For the baseline analyses, we excluded 5921 participants because they had a pre-baseline cancer diagnosis, were in the top or bottom $1 \%$ of the baseline energy distribution, had reported history of a heart attack, angina or diabetes at baseline possibly resulting in a changed diet, were diagnosed with prostate cancer during follow-up but we were unable to determine aggressiveness of the tumour, or they had missing data on soft drink consumption or any of the confounders. Thus, we had 35393 participants available for our baseline analyses (Fig. 1).

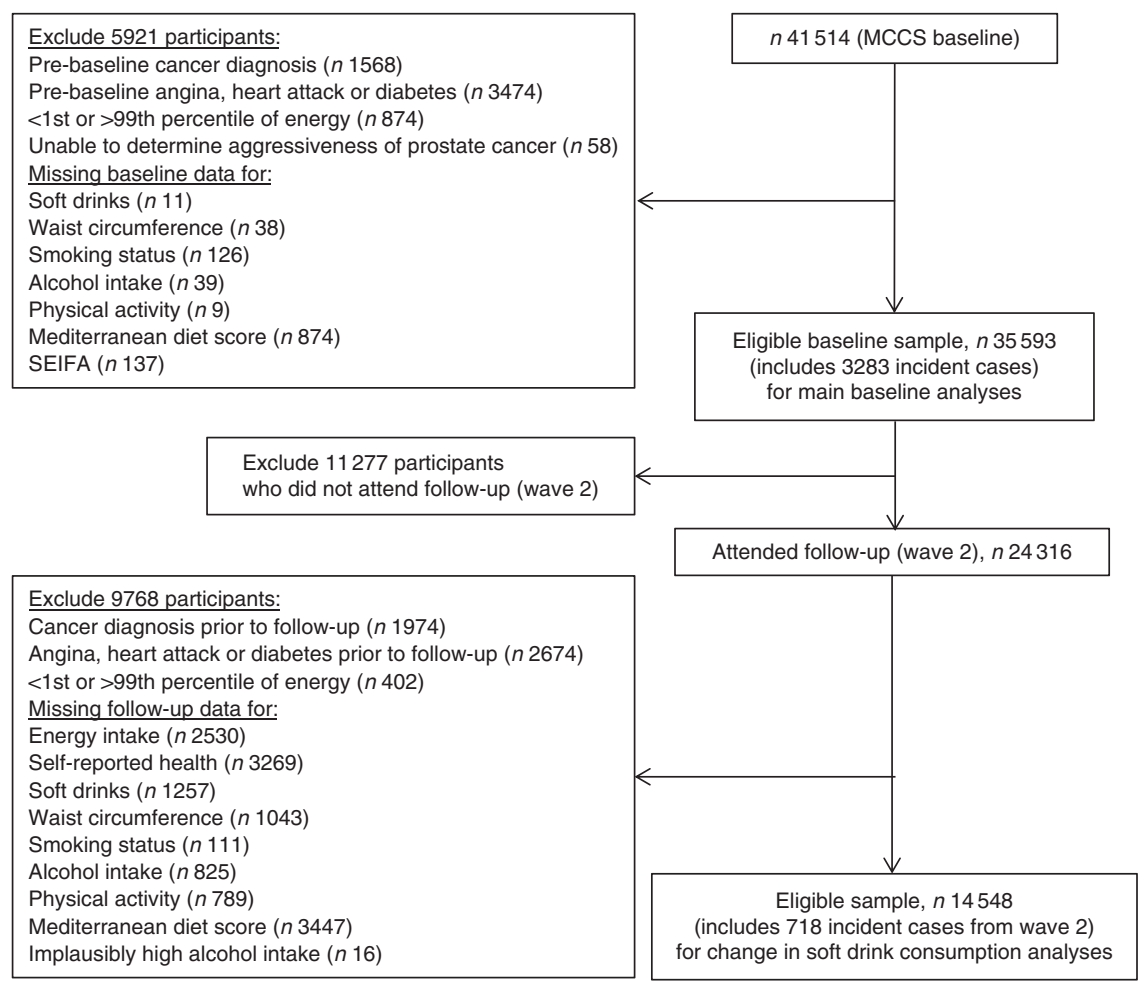

Fig. 1 Flowchart showing participants included and excluded in each analysis (MCCS, Melbourne Collaborative Cohort Study; SEIFA, Socio-Economic Indexes for Areas) 
Of these, 24316 participants also attended the wave 2 survey. After excluding those with a cancer diagnosis or a history of a heart attack, angina or diabetes prior to wave 2 (as these conditions might have motivated changes in soft drink consumption and be associated with the outcome), and further excluding those in the extremes of the energy distribution or with missing confounder or exposure data at follow-up, there were 14548 participants who had data at both baseline and wave 2 (Fig. 1).

This study was conducted according to the guidelines laid down in the Declaration of Helsinki and all procedures involving human subjects/patients were approved by the Cancer Council Victoria Human Research Ethics Committee. Written informed consent was obtained from all participants at baseline and wave 2 .

\section{Study protocol}

At baseline, participants completed a 121-item FFQ including separate questions about the number of times in the past year they had consumed regular (sugar-sweetened) or diet (artificially sweetened) soft drinks ('never or less than once per month'; '1-3 per month'; '1 per week'; '2-4 per week'; '5-6 per week'; '1 per day'; '2-3 per day'; ' $4-5$ per day'; ' $6+$ per day'). Other data from the FFQ were used to calculate a Mediterranean diet score as described previously $^{(10)}$. Height, weight and waist circumference were measured using standard methods and questions about smoking, leisure-time physical activity and intake of alcoholic beverages were completed $^{(11)}$. At wave 2 an updated FFQ was completed which included questions about the number of glasses of regular or diet soft drinks consumed per day. Weight and waist circumference were measured again, but height was not, because it was assumed not to have changed since baseline. Questions were completed on smoking, physical activity and consumption of alcoholic beverages.

\section{Case ascertainment}

Incident cancer cases were ascertained from the Victorian Cancer Registry or the Australian Cancer Database as the earliest diagnosis of an invasive or metastatic primary cancer (we excluded in situ or benign tumours). Mortality data, including cause of death, were obtained from the National Death Index, the Australian Bureau of Statistics or were coded by cancer registry staff.

\section{Statistical methods}

Hazard ratios (HR) and 95\% CI for obesity-related cancer risk associated with soft drink consumption were estimated using Cox proportional hazards regression models with age as the time metric. Participants were followed up from baseline to the earliest of the date of diagnosis of any cancer, date of death, date last known to be in Australia or 30 June 2013 (the date that ascertainment of cancer diagnoses by the cancer registry was complete). The event of interest was diagnosis with liver, advanced prostate, ovary, gallbladder, kidney, colorectum, oesophagus (adenocarcinoma), postmenopausal breast, pancreas, endometrium or stomach (cardia) cancer. For the categorical analysis, we modelled frequency of soft drink consumption in five categories: never or $<1$ time/month; $1-3$ times/month; 1-6 times/week; 1 time/d; and $>1$ time/d. To estimate linear trends on a log hazard scale, we assigned the median daily equivalent frequency to each of the five categories of soft drink consumption and used this as a continuous variable. For the specific obesity-related cancers with sufficient cases (more than 100), we fitted Cox proportional hazards regression models using four categories of soft drink consumption (never or $<1$ time/month; 1-3 times/month; 1- 6 times/week; $\geq 1$ time/d) and assigned the median daily equivalent frequencies to each of these four categories. To investigate departures from linearity in the relationship between soft drink consumption and obesity-related cancers, the likelihood ratio test was used to compare the linear and categorical models. Potential confounders were identified from a directed acyclic graph ${ }^{(12)}$. The model with sugarsweetened soft drink as the exposure was adjusted for socio-economic position (quintiles of area-based relative socio-economic disadvantage), alcohol intake (lifetime abstainers; ex-drinkers; low intake (1-39 g/d for males, $1-19 \mathrm{~g} / \mathrm{d}$ for females); moderate intake $(40-59 \mathrm{~g} / \mathrm{d}$ for males, $20-39 \mathrm{~g} / \mathrm{d}$ for females); high intake $(\geq 60 \mathrm{~g} / \mathrm{d}$ for males, $\geq 40 \mathrm{~g} / \mathrm{d}$ for females)), country of birth (Australia/New Zealand; UK; Italy; Greece), Mediterranean diet score, physical activity (summary score based on the relative energy expenditure of participation in vigorous, moderate and walking activity, categorised as low ( $>0$ and $<4$ ), moderate $(\geq 4$ and $<6)$ and high $\left.(\geq 6)^{(11)}\right)$, sex and smoking status (never smoked; former, short-term quitter $<10$ years; former, long-term quitter $\geq 10$ years; current light smoker $<15$ cigarettes/d; current heavy smoker $\geq 15$ cigarettes/d). The model with artificially sweetened soft drink as the exposure was additionally adjusted for frequency of sugarsweetened soft drink consumption and waist circumference (centimetres). As a secondary analysis, we also included waist circumference and total energy intake in the sugarsweetened soft drink model.

To estimate HR and 95\% CI for obesity-related cancer risk associated with change in sugar-sweetened soft drink consumption between baseline and wave 2, we fitted Cox regression models using age as the time metric and following participants from wave 2 until the same end date used for the baseline analyses. At baseline, sweetened soft drink was reported as a daily frequency whereas at wave 2 it was reported as the number of glasses per day. Therefore, we have assumed at baseline that one glass was consumed on each occasion. We created five sugarsweetened soft drink change categories: never consumers (no consumption on either occasion); maintained low intake $(<1$ time $/ \mathrm{d}$ at baseline and $<1$ glass/d at wave 2 ); maintained high intake ( $\geq 1$ time/d at baseline 
and $\geq 1$ glass/d at wave 2 ); decreased intake ( $<1$ time/d at baseline and none at wave 2 ; or $\geq 1$ time/d at baseline and none or $<1$ glass/d at wave 2); increased intake (none at baseline and $<1$ glass/d or $\geq 1$ glass/d at wave 2 ; or $<1$ time/d at baseline and $\geq 1$ glass/d at wave 2 ). This model included the same confounders as the baseline analysis, as well as alcohol intake, Mediterranean diet score, physical activity and smoking status from the wave 2 survey.

We performed sensitivity analyses: excluding the first 2 years of follow-up to assess the possibility that the observed associations were distorted by pre-existing disease; not adjusting the artificially sweetened soft drink model for frequency of sugar-sweetened soft drink consumption; restricting analyses to those who only consumed sugar-sweetened soft drinks or to those who only consumed artificially sweetened soft drinks.

Tests based on Schoenfeld residuals showed no evidence of violation of the proportional hazards assumption, except for sex, so we stratified for this variable in our main analyses for all obesity-related cancers. All statistical tests were two sided, with $P<0.05$ considered statistically significant. Statistical analyses were performed using the statistical software package Stata/MP version 14.1.

\section{Results}

We included in the baseline analysis data for 35593 participants who developed 3283 incident obesity-related cancers (Table 1). Table 2 shows baseline characteristics by frequency of soft drink consumption. The most frequent consumers of sugar-sweetened soft drinks had larger body size, higher total sugar intake, were more likely to be male, to be socio-economically disadvantaged and to have less healthy lifestyles (i.e. more likely to be smokers, be less active and drink artificially sweetened soft drinks). The most frequent consumers of artificially sweetened soft

Table 1 Distribution of cancer sites for 35593 participants of the Melbourne Collaborative Cohort Study who developed 3283 incident obesity-related cancers*

\begin{tabular}{lrr}
\hline Cancer site & $n$ & $\%$ \\
\hline Liver & 52 & $1 \cdot 6$ \\
Aggressive prostate & 433 & $13 \cdot 2$ \\
Ovary & 130 & 4.0 \\
Gallbladder & 31 & $0 \cdot 9$ \\
Kidney & 146 & 4.4 \\
Colorectum & 1055 & $32 \cdot 1$ \\
Oesophagus & 60 & $1 \cdot 8$ \\
Postmenopausal breast & 946 & $28 \cdot 8$ \\
Pancreas & 98 & 3.0 \\
Endometrium & 167 & $5 \cdot 1$ \\
Gastric cardia & 165 & $5 \cdot 0$ \\
All obesity-related cancers & 3283 & $100 \cdot 0$ \\
\hline
\end{tabular}

*Obesity-related cancers according to the World Cancer Research Fund (http://www.wcrf.org/int/cancer-facts-figures/link-between-lifestyle-cancer-risk/ weight-cancer). drinks also had larger body size, although they were not notably different from those who consumed less artificially sweetened soft drink in terms of other characteristics. There was a consistent trend of increasing waist circumference with increasing frequency of intake of sugar-sweetened soft drink consumption (Table 2), with a mean difference of $7.7 \mathrm{~cm}$ between the lowest and highest consumption group (the mean difference in waist circumference was $3.7 \mathrm{~cm}$ for men and $5.5 \mathrm{~cm}$ for women). For artificially sweetened soft drinks the difference in mean waist circumference across frequency groups was $5.1 \mathrm{~cm}$ (which was the same for both men and women; Table 2).

For sugar-sweetened soft drinks, the HR for obesityrelated cancers increased modestly as frequency of consumption increased ( $P$-trend $=0.007$; Table 3 ). Further adjustment for waist circumference only slightly attenuated the HR and adjustment for total energy intake changed the HR only minimally. The models for sugarsweetened beverage showed no departures from linearity $(P>0.24)$. For artificially sweetened soft drinks there was no association between frequency of consumption and obesity-related cancer risk, and the results were not changed by including total energy intake in the models.

For seven of the obesity-related cancers with sufficient cases (more than 100), there were generally positive associations with sugar-sweetened soft drink consumption (Table 4), although only for colorectal cancer (with over 1000 cases) did this reach statistical significance for the highest intake group $(\geq 1 / d)$ compared with never consumers (HR $=1 \cdot 28 ; 95 \%$ CI 1.04, 1.57). For postmenopausal breast cancer, the highest risk was associated with 1-6 drinks/week (HR $=1.21 ; 95 \%$ CI 1.03, 1.43). For artificially sweetened soft drinks there was little evidence of any association except for a non-significant positive association with ovarian cancer. There were no departures from linearity in any of the specific obesity-related cancer models (all $P>0.05$ ), except for the gastric cancer and sugarsweetened beverage model $(P=0.02)$ and the colorectal cancer and artificially sweetened beverage model $(P=0.05)$.

There were data for 14548 participants, diagnosed with 718 obesity-related cancers after wave 2 , in our analyses of change in frequency of sugar-sweetened soft drink consumption. No associations were observed for any of the sugar-sweetened soft drink change categories relative to those who never consumed sugar-sweetened soft drinks (Table 5). Waist circumference increased over time by a similar amount irrespective of the consumption of sugarsweetened soft drinks and changes in this. For men, the mean increase in waist circumference between baseline and wave 2 for non-consumers of sugar-sweetened soft drinks was 5.3 (SD 7.1) $\mathrm{cm}$ and for those who increased intake it was 6.0 (SD 7.3). For women, the increases for the same groups were $7.9 \mathrm{~cm}(\mathrm{SD} 7.9) \mathrm{cm}$ and $9.0(\mathrm{SD} 8.1) \mathrm{cm}$, respectively.

Associations between frequency of soft drink consumption and obesity-related cancers were similar after 
Table 2 Baseline characteristics by soft drink intake categories; Melbourne Collaborative Cohort Study, 1990-1994

\begin{tabular}{|c|c|c|c|c|c|c|c|c|c|c|}
\hline & \multicolumn{10}{|c|}{ Frequency of sugar-sweetened soft drink consumption } \\
\hline & \multicolumn{2}{|c|}{$\begin{array}{l}\text { Never or }<1 \text { time/ } \\
\text { month }(n 18616)\end{array}$} & \multicolumn{2}{|c|}{$\begin{array}{c}1-3 \text { times/month } \\
(n 6215)\end{array}$} & \multicolumn{2}{|c|}{$\begin{array}{c}1-6 \text { times/week } \\
(n \text { 7813) }\end{array}$} & \multicolumn{2}{|c|}{$\begin{array}{l}1 \text { time/d } \\
(n 1938)\end{array}$} & \multicolumn{2}{|c|}{$\begin{array}{l}>1 \text { time/d } \\
(n \text { 1011) }\end{array}$} \\
\hline & $\begin{array}{l}\text { Mean, } \\
\text { median or } \\
n\end{array}$ & $\begin{array}{c}\text { SD, IQR } \\
\text { or } \%\end{array}$ & $\begin{array}{l}\text { Mean, } \\
\text { median or } \\
n\end{array}$ & $\begin{array}{l}\text { SD, IQR } \\
\text { or } \%\end{array}$ & $\begin{array}{l}\text { Mean, } \\
\text { median or } \\
n\end{array}$ & $\begin{array}{l}\text { SD, IQR } \\
\text { or } \%\end{array}$ & $\begin{array}{l}\text { Mean, } \\
\text { median or } \\
n\end{array}$ & $\begin{array}{l}\mathrm{SD}, \mathrm{IQR} \\
\text { or } \%\end{array}$ & $\begin{array}{l}\text { Mean, } \\
\text { median or } \\
n\end{array}$ & $\begin{array}{l}\text { SD, IQR } \\
\text { or } \%\end{array}$ \\
\hline Age (years), mean and SD & $55 \cdot 6$ & 8.6 & 53.6 & 8.5 & 53.4 & 8.6 & 54.6 & 8.7 & 54.9 & 8.5 \\
\hline BMI $\left(\mathrm{kg} / \mathrm{m}^{2}\right)$, mean and SD & $26 \cdot 5$ & 4.4 & $26 \cdot 6$ & $4 \cdot 1$ & $27 \cdot 1$ & 4.3 & $27 \cdot 5$ & 4.4 & 28.4 & 4.5 \\
\hline Waist $(\mathrm{cm})$, mean and SD & $83 \cdot 4$ & $12 \cdot 7$ & $84 \cdot 4$ & $12 \cdot 4$ & $86 \cdot 8$ & 12.5 & 88.2 & 12.5 & $91 \cdot 1$ & $12 \cdot 9$ \\
\hline $\begin{array}{l}\text { Alcohol }(\mathrm{g} / \mathrm{d}), \text { median and } \\
\text { IQR }\end{array}$ & $3 \cdot 7$ & $0-16 \cdot 4$ & 4.6 & $0-16 \cdot 8$ & 4.9 & $0-17 \cdot 9$ & 5 & $0-18.4$ & $5 \cdot 3$ & $0-21 \cdot 1$ \\
\hline MDS, median and IQR & 4 & $3-6$ & 4 & $3-6$ & 4 & $3-6$ & 4 & $3-6$ & 4 & $3-6$ \\
\hline $\begin{array}{l}\text { Sugar }(\mathrm{g} / \mathrm{d}) \text {, mean and SD } \\
\text { Country of birth, } n \text { and \% }\end{array}$ & $115 \cdot 8$ & 61.5 & $123 \cdot 1$ & $61 \cdot 1$ & $132 \cdot 6$ & 63.2 & $151 \cdot 4$ & $66 \cdot 4$ & $191 \cdot 2$ & $74 \cdot 6$ \\
\hline Australia/New Zealand & 12801 & $68 \cdot 8$ & 4524 & $72 \cdot 8$ & 5727 & $73 \cdot 3$ & 1179 & $60 \cdot 8$ & 500 & 49.5 \\
\hline UK & 1490 & 8.0 & 432 & $7 \cdot 0$ & 519 & $6 \cdot 6$ & 144 & 7.4 & 47 & 4.6 \\
\hline Italy & 2071 & $11 \cdot 1$ & 676 & 10.9 & 932 & 11.9 & 453 & 23.4 & 359 & $35 \cdot 5$ \\
\hline Greece & 2254 & $12 \cdot 1$ & 583 & 9.4 & 635 & $8 \cdot 1$ & 162 & 8.4 & 105 & $10 \cdot 4$ \\
\hline Male, $n$ and $\%$ & 6068 & $32 \cdot 6$ & 2560 & $41 \cdot 2$ & 3906 & $50 \cdot 0$ & 1001 & $51 \cdot 7$ & 566 & $56 \cdot 0$ \\
\hline $\begin{array}{l}\text { SEIFA Q5 (least } \\
\text { disadvantaged), } n \text { and } \%\end{array}$ & 4955 & $26 \cdot 6$ & 1759 & $28 \cdot 3$ & 2093 & $26 \cdot 8$ & 419 & $21 \cdot 6$ & 178 & $17 \cdot 6$ \\
\hline $\begin{array}{l}\text { Physical activity score } \geq 6 \text {, } \\
n \text { and } \%\end{array}$ & 4387 & $23 \cdot 6$ & 1449 & $23 \cdot 3$ & 1831 & $23 \cdot 4$ & 339 & $17 \cdot 5$ & 173 & $17 \cdot 1$ \\
\hline Current smoker, $n$ and $\%$ & 2064 & $11 \cdot 1$ & 580 & $9 \cdot 3$ & 890 & 11.4 & 277 & $14 \cdot 3$ & 173 & $17 \cdot 1$ \\
\hline \multirow[t]{4}{*}{ Diet soft drink $>1 / \mathrm{d}, n$ and $\%$} & 401 & $2 \cdot 2$ & 70 & $1 \cdot 1$ & 115 & 1.5 & 58 & $3 \cdot 0$ & 116 & $11 \cdot 5$ \\
\hline & \multicolumn{10}{|c|}{ Frequency of artificially sweetened soft drink consumption } \\
\hline & \multicolumn{2}{|c|}{$\begin{array}{l}\text { Never or }<1 \text { time/ } \\
\text { month }(n 26661)\end{array}$} & \multicolumn{2}{|c|}{$\begin{array}{l}1-3 \text { times/month } \\
(\text { ( } 2948)\end{array}$} & \multicolumn{2}{|c|}{$\begin{array}{l}\text { 1-6 times/week } \\
(n \text { 3926) }\end{array}$} & \multicolumn{2}{|c|}{$\begin{array}{l}1 \text { time/d } \\
(n 1298)\end{array}$} & \multicolumn{2}{|c|}{$\begin{array}{l}>1 \text { time/d } \\
(n 760)\end{array}$} \\
\hline & $\begin{array}{l}\text { Mean, } \\
\text { median or } \\
n\end{array}$ & $\begin{array}{l}\text { SD, IQR } \\
\text { or \% }\end{array}$ & $\begin{array}{l}\text { Mean, } \\
\text { median or } \\
n\end{array}$ & $\begin{array}{l}\mathrm{SD}, \mathrm{IQR} \\
\text { or } \%\end{array}$ & $\begin{array}{l}\text { Mean, } \\
\text { median or } \\
n\end{array}$ & $\begin{array}{l}\text { SD, IQR } \\
\text { or } \%\end{array}$ & $\begin{array}{l}\text { Mean, } \\
\text { median or } \\
n\end{array}$ & $\begin{array}{l}\text { SD, IQR } \\
\text { or } \%\end{array}$ & $\begin{array}{l}\text { Mean, } \\
\text { median or } \\
n\end{array}$ & $\begin{array}{l}\text { SD, IQR } \\
\text { or } \%\end{array}$ \\
\hline Age (years), mean and SD & $55 \cdot 1$ & 8.7 & 53.4 & $8 \cdot 4$ & 53.1 & 8.4 & 53.7 & 8.6 & 53.9 & 8.5 \\
\hline BMI $\left(\mathrm{kg} / \mathrm{m}^{2}\right)$, mean and SD & $26 \cdot 4$ & 4.2 & $27 \cdot 4$ & 4.3 & $27 \cdot 9$ & 4.5 & 28.4 & 4.7 & $29 \cdot 1$ & $5 \cdot 1$ \\
\hline Waist $(\mathrm{cm})$, mean and SD & $84 \cdot 1$ & $12 \cdot \overline{6}$ & 86 & $12 \cdot 6$ & $86 \cdot 8$ & $12 \cdot 8$ & 87.6 & $13 \cdot 1$ & 89.2 & 13.9 \\
\hline $\begin{array}{l}\text { Alcohol }(g / d), \text { median and } \\
\text { IQR }\end{array}$ & $4 \cdot 3$ & $0-17 \cdot 2$ & 3.5 & $0-15 \cdot 6$ & $4 \cdot 3$ & $0-16 \cdot 1$ & $4 \cdot 8$ & $0-17 \cdot 0$ & $2 \cdot 7$ & $0-17 \cdot 0$ \\
\hline MDS, median and IQR & 4 & $3-6$ & 4 & $3-6$ & 4 & $3-6$ & 4 & $3-6$ & 4 & $3-6$ \\
\hline $\begin{array}{l}\text { Sugar }(\mathrm{g} / \mathrm{d}) \text {, mean and SD } \\
\text { Country of birth, } n \text { and \% }\end{array}$ & 125 & 64.4 & $121 \cdot 4$ & 63.2 & 123.5 & $62 \cdot 0$ & $129 \cdot 8$ & $66 \cdot 1$ & $131 \cdot 3$ & 69.8 \\
\hline Australia/New Zealand & 18489 & $69 \cdot 3$ & 1972 & $66 \cdot 9$ & 2803 & 71.4 & 914 & $70 \cdot 4$ & 553 & $72 \cdot 8$ \\
\hline UK & 2026 & 7.6 & 174 & 5.9 & 286 & $7 \cdot 3$ & 94 & $7 \cdot 2$ & 52 & 6.8 \\
\hline Italy & 3392 & $12 \cdot 7$ & 357 & $12 \cdot 1$ & 428 & $10 \cdot 9$ & 194 & 14.9 & 120 & $15 \cdot 8$ \\
\hline Greece & 2754 & $10 \cdot 3$ & 445 & $15 \cdot 1$ & 409 & $10 \cdot 4$ & 96 & 7.4 & 35 & 4.6 \\
\hline Male, $n$ and $\%$ & 10641 & 39.9 & 1207 & 40.9 & 1525 & 38.8 & 451 & 34.7 & 277 & 36.4 \\
\hline $\begin{array}{l}\text { SEIFA Q5 (least } \\
\text { disadvantaged), } n \text { and \% }\end{array}$ & 7129 & $26 \cdot 7$ & 762 & $25 \cdot 8$ & 1052 & $26 \cdot 8$ & 291 & $22 \cdot 4$ & 170 & $22 \cdot 4$ \\
\hline $\begin{array}{l}\text { Physical activity score } \geq 6 \text {, } \\
n \text { and \% }\end{array}$ & 6051 & $22 \cdot 7$ & 680 & $23 \cdot 1$ & 990 & $25 \cdot 2$ & 299 & 23.0 & 159 & $20 \cdot 9$ \\
\hline Current smoker, $n$ and \% & 3046 & 11.4 & 300 & $10 \cdot 2$ & 403 & $10 \cdot 3$ & 143 & 11.0 & 92 & $12 \cdot 1$ \\
\hline $\begin{array}{l}\text { Sugar-sweetened soft drink } \\
>1 / \mathrm{d}, n \text { and } \%\end{array}$ & 754 & $2 \cdot 8$ & 50 & $1 \cdot 7$ & 59 & 1.5 & 32 & $2 \cdot 5$ & 116 & $15 \cdot 3$ \\
\hline
\end{tabular}

IQR, interquartile range (25th-75th percentile); MDS, Mediterranean diet score; SEIFA, Socio-Economic Indexes for Areas; Q5, 5th quartile.

excluding the first 2 years of follow-up; restricting the sugar-sweetened soft drink analyses to those who did not consume artificially sweetened soft drinks; restricting the artificially sweetened soft drink analyses to those who did not consume sugar-sweetened soft drinks; and not adjusting the artificially sweetened soft drink model for sugar-sweetened soft drink consumption (data not shown).

\section{Discussion}

More frequent consumption of sugar-sweetened soft drinks at baseline was associated with a higher waist circumference and a modest increase in risk for obesityrelated cancer overall. Consumption of artificially sweetened soft drinks was also associated with a higher waist circumference but not with obesity-related cancer risk. 
Table 3 Hazard ratios (HR) for obesity-related cancer and soft drink consumption at baseline; Melbourne Collaborative Cohort Study, 1990-1994

\begin{tabular}{|c|c|c|c|c|c|c|c|c|}
\hline \multirow[b]{2}{*}{ Frequency of consumption } & \multicolumn{5}{|c|}{ Sugar-sweetened soft drinks } & \multicolumn{3}{|c|}{ Artificially sweetened soft drinks } \\
\hline & Cases $(n)$ & $\mathrm{HR}^{*}$ & $95 \% \mathrm{Cl}$ & $\mathrm{HR} \dagger$ & $95 \% \mathrm{Cl}$ & Cases $(n)$ & HR $\ddagger$ & $95 \% \mathrm{Cl}$ \\
\hline Never or $<1 /$ month & 1724 & 1.00 & Ref. & 1.00 & Ref. & 2498 & 1.00 & Ref. \\
\hline $1-3 /$ month & 538 & 1.03 & $0.94,1.14$ & 1.03 & $0.94,1.14$ & 233 & 0.87 & $0.76,1.00$ \\
\hline 1-6/week & 718 & $1 \cdot 12$ & $1.02,1 \cdot 22$ & 1.09 & $1.00,1.20$ & 376 & 1.04 & $0.93,1.17$ \\
\hline $1 / d$ & 198 & $1 \cdot 19$ & $1.03,1.38$ & $1 \cdot 16$ & $1.00,1.35$ & 102 & 0.81 & $0.66,0.99$ \\
\hline$>1 / d$ & 105 & $1 \cdot 18$ & $0.97,1.45$ & $1 \cdot 14$ & $0.93,1.39$ & 74 & 1.00 & $0.79,1.27$ \\
\hline Linear model & 3283 & $1 \cdot 10$ & $1.03,1.18$ & 1.08 & $1.01,1.16$ & 3283 & 0.98 & $0.90,1.07$ \\
\hline$P \S$ & & \multicolumn{2}{|c|}{$0.007 / 0.25$} & \multicolumn{2}{|c|}{$0.03 / 0.39$} & & \multicolumn{2}{|c|}{$0.61 / 0.03$} \\
\hline
\end{tabular}

Ref., reference category; SEIFA, Socio-Economic Indexes for Areas.

${ }^{*}$ Adjusted for SEIFA, country of birth, alcohol intake, smoking status, physical activity, Mediterranean diet score and stratified by sex (due to non-proportional hazards).

†Adjusted for all variables mentioned above plus waist circumference and stratified by sex (due to non-proportional hazards).

$\ddagger$ Adjusted for all variables mentioned above plus sugar-sweetened soft drink consumption and waist circumference and stratified by sex (due to nonproportional hazards).

$\S P$ for trend/ $P$ for departure from linearity.

Increasing or decreasing sugar-sweetened soft drink intake between baseline and wave 2 was not associated with cancer risk relative to non-consumption of sugarsweetened soft drinks.

The main weakness of our study is that intakes of sugarsweetened and artificially sweetened soft drinks collected by self-report may not be accurate and we have not specifically validated these measures. The proportion of MCCS participants who reported consuming sugar-sweetened soft drinks or artificially sweetened soft drinks at least once daily was small, 8.3 and $5.8 \%$, respectively. In the 2011-12 Australian Health Survey ${ }^{(1)} 31 \%$ of people aged $31-50$ years and $23 \%$ of those aged 51-70 years reported consuming soft drink the previous day, which is much higher than we observed for MCCS participants who would have been of a similar age at recruitment in the early 1990s. On the other hand, among the people aged 71 years or older in the Australian Health Survey, who would be part of the same birth cohort as MCCS participants, only $13 \%$ reported consuming soft drink the previous day. The MCCS participants had a standardised mortality ratio of $0 \cdot 43$, which is consistent with being healthier than the general population ${ }^{(13)}$, and so they might be expected to consume fewer soft drinks than the general population.

Strengths of our study include the large number of cases of obesity-related cancers and the objective assessment of the outcomes. We have been able to measure and control for many confounders, although we cannot exclude residual confounding. In particular, consumption of sugar-sweetened soft drinks was associated with other unhealthy behaviours (i.e. less physical activity, more smoking and more, but still low, alcohol consumption), which may not have been adequately controlled for.

A recent meta-analysis and review of sweetened carbonated beverage consumption and cancer risk found no association overall or for individual cancer sites including pancreas, kidney, adenocarcinoma of the oesophagus, colon, gastric cardia, prostate, breast and ovary ${ }^{(5)}$, which are included in the current study.
The meta-analysis did not differentiate between sugarsweetened and artificially sweetened drinks, although the discussion did not suggest any systematic differences between these. Another major limitation of that metaanalysis was the lack of consideration of any measures of obesity. For analyses with sugar-sweetened soft drinks we assumed that increased consumption of sugarsweetened soft drinks would lead to increased body size which in turn could increase the risk of the specific cancers. Under this assumption it is not appropriate to adjust for body size, which was included only in a secondary analysis ${ }^{(12)}$. Although the magnitude of the HR was only minimally changed by the inclusion of waist circumference, the linear association was no longer statistically significant. For artificially sweetened soft drinks we assumed that the relationship we observed between frequency of consumption and waist circumference was due to people with greater body size choosing artificially sweetened soft drinks rather than sugar-sweetened soft drinks. In that case it would be necessary to adjust for body size in the base model as it would be a confounder, although there is now some evidence that artificially sweetened beverage consumption is associated with weight gain ${ }^{(14)}$. Nevertheless, there was no association for artificially sweetened soft drinks and obesity-related cancers irrespective of whether waist circumference was adjusted for or not. A study of soft drink intake and haematopoietic cancers, based on the possibility that aspartame in diet drinks could be metabolised to formaldehyde, a known carcinogen, found some evidence for an association but it was not consistent between men and women and was also seen for regular soft drinks ${ }^{(15)}$. While these cancers are not obesity-related, the findings tend to support the safety of aspartame-containing diet soft drinks.

For a sub-study of people with data from baseline and wave 2, waist circumference increased similarly over time for people who continued to abstain from sugarsweetened soft drinks, those who maintained low or high 
Table 4 Hazard ratios (HR) for specific obesity-related cancers and soft drink consumption at baseline; Melbourne Collaborative Cohort Study, 1990-1994

\begin{tabular}{|c|c|c|c|c|c|c|c|}
\hline \multirow[b]{2}{*}{ Cancer site } & \multirow[b]{2}{*}{ Frequency of consumption } & \multicolumn{3}{|c|}{ Sugar-sweetened soft drinks } & \multicolumn{3}{|c|}{ Artificially sweetened soft drinks } \\
\hline & & Cases $(n)$ & $\mathrm{HR}^{*}$ & $95 \% \mathrm{Cl}$ & Cases $(n)$ & $\mathrm{HR} \dagger$ & $95 \% \mathrm{Cl}$ \\
\hline \multirow[t]{6}{*}{ Aggressive prostate } & $<1 /$ month & 189 & 1.00 & Ref. & 333 & 1.00 & Ref. \\
\hline & $1-3 /$ month & 77 & 1.07 & $0.82,1.40$ & 33 & 0.94 & $0.65,1.36$ \\
\hline & 1-6/week & 122 & 1.15 & $0.91,1.45$ & 50 & 1.09 & $0.80,1.48$ \\
\hline & $\geq 1 / d$ & 45 & 1.08 & $0.78,1.50$ & 17 & 0.81 & $0.49,1.33$ \\
\hline & Linear model & 433 & $1 \cdot 12$ & $0.83,1.51$ & 433 & 0.91 & $0.60,1.38$ \\
\hline & $P \S$ & \multicolumn{4}{|c|}{$0.47 / 0.64$} & \multicolumn{2}{|c|}{$0.66 / 0.60$} \\
\hline \multirow[t]{6}{*}{ Ovary } & $<1 /$ month & 75 & 1.00 & Ref. & 75 & 1.00 & Ref. \\
\hline & 1-3/month & 20 & 0.97 & $0.59,1.59$ & 20 & 0.80 & $0.38,1.69$ \\
\hline & 1-6/week & 24 & 1.07 & $0.68,1.70$ & 24 & 1.39 & $0.83,2.34$ \\
\hline & $\geq 1 / d$ & 11 & 1.35 & $0.71,2.56$ & 11 & 1.37 & $0 \cdot 72,2 \cdot 61$ \\
\hline & Linear model & 130 & 1.32 & $0.73,2.41$ & 130 & 1.51 & $0.84,2.73$ \\
\hline & $P \S$ & \multicolumn{4}{|c|}{$0.36 / 0.96$} & \multicolumn{2}{|c|}{$0.17 / 0.60$} \\
\hline \multirow{6}{*}{ Kidney } & $<1 /$ month & 64 & 1.00 & Ref. & 114 & 1.00 & Ref. \\
\hline & $1-3 /$ month & 31 & 1.43 & $0.92,2 \cdot 20$ & 11 & 0.71 & $0.38,1.36$ \\
\hline & 1-6/week & 33 & $1 \cdot 13$ & $0.73,1.73$ & 12 & 0.66 & $0.36,1.22$ \\
\hline & $\geq 1 / d$ & 18 & 1.48 & $0.87,2.53$ & 9 & 0.92 & $0.46,1.84$ \\
\hline & Linear model & 146 & 1.32 & $0.79,2.19$ & 146 & 0.78 & $0.40,1.55$ \\
\hline & $P \S$ & \multicolumn{4}{|c|}{$0.29 / 0.28$} & \multicolumn{2}{|c|}{$0.48 / 0.33$} \\
\hline \multirow[t]{6}{*}{ Colorectum } & $<1 /$ month & 536 & 1.00 & Ref. & 802 & 1.00 & Ref. \\
\hline & $1-3 /$ month & 194 & $1 \cdot 17$ & $0.99,1.38$ & 77 & 0.87 & $0.68,1.11$ \\
\hline & 1-6/week & 213 & 0.99 & $0.85,1.17$ & 125 & $1 \cdot 15$ & $0.95,1.40$ \\
\hline & $\geq 1 / d$ & 112 & 1.28 & $1.04,1.57$ & 51 & 0.79 & $0.60,1.06$ \\
\hline & Linear model & 1055 & $1 \cdot 17$ & $0.96,1.43$ & 1055 & 0.91 & $0.71,1 \cdot 17$ \\
\hline & $P \S$ & \multicolumn{4}{|c|}{$0.12 / 0.06$} & \multicolumn{2}{|c|}{$0.46 / 0.05$} \\
\hline \multirow[t]{6}{*}{ Postmenopausal breast } & $<1 /$ month & 547 & 1.00 & Ref. & 716 & 1.00 & Ref. \\
\hline & $1-3 /$ month & 138 & 0.90 & $0.75,1.08$ & 69 & 0.94 & $0.73,1.22$ \\
\hline & 1-6/week & 198 & 1.21 & $1.03,1.43$ & 101 & 0.90 & $0.72,1 \cdot 12$ \\
\hline & $\geq 1 / d$ & 63 & $1 \cdot 11$ & $0.85,1.45$ & 60 & 0.95 & $0.73,1.25$ \\
\hline & Linear model & 946 & 1.26 & $1.00,1.58$ & 946 & 0.92 & $0 \cdot 71,1 \cdot 18$ \\
\hline & $P \S$ & \multicolumn{4}{|c|}{$0.05 / 0.09$} & \multicolumn{2}{|c|}{$0.51 / 0.71$} \\
\hline \multirow{6}{*}{ Endometrium } & $<1 /$ month & 94 & 1.00 & Ref. & 125 & 1.00 & Ref. \\
\hline & $1-3 /$ month & 30 & $1 \cdot 12$ & $0.74,1.69$ & 9 & 0.58 & $0.29,1 \cdot 16$ \\
\hline & 1-6/week & 32 & 1.09 & $0.73,1.63$ & 23 & $1 \cdot 11$ & $0.70,1.77$ \\
\hline & $\geq 1 / d$ & 11 & 1.02 & $0.54,1.91$ & 10 & 0.81 & $0.42,1.55$ \\
\hline & Linear model & \multirow{2}{*}{\multicolumn{4}{|c|}{$0.88 / 0.84$}} & \multirow{2}{*}{\multicolumn{2}{|c|}{$0 \cdot 78 / 0 \cdot 17$}} \\
\hline & $P \S$ & & & & & & \\
\hline \multirow[t]{6}{*}{ Gastric cardia } & $<1 /$ month & 96 & 1.00 & Ref. & 123 & 1.00 & Ref. \\
\hline & $1-3 /$ month & 14 & 0.48 & $0.27,0.85$ & 9 & 0.86 & $0.42,1.73$ \\
\hline & $1-6 /$ week & 33 & 0.88 & $0.59,1.31$ & 23 & 1.46 & $0.92,2.34$ \\
\hline & $\geq 1 / d$ & 22 & 1.17 & $0.73,1.89$ & 10 & 1.03 & $0.53,1.98$ \\
\hline & Linear model & 165 & 1.24 & $0.77,1.99$ & 165 & 1.24 & $0.70,2 \cdot 18$ \\
\hline & $P \S$ & & & 7/0.02 & & & $6 / 0 \cdot 33$ \\
\hline
\end{tabular}

Ref., reference category; SEIFA, Socio-Economic Indexes for Areas.

${ }^{*}$ Adjusted for SEIFA, country of birth, alcohol intake, smoking status, physical activity, Mediterranean diet score (and sex in models for kidney, colorectal and gastric cardia cancer).

†Adjusted for all variables mentioned above plus sugar-sweetened soft drink consumption and waist circumference.

$\S P$ for trend $/ P$ for departure from linearity.

Table 5 Hazard ratios (HR) for obesity-related cancer and change in sugar-sweetened soft drink consumption between baseline (1990-1994) and wave 2 (2003-2007); Melbourne Collaborative Cohort Study

\begin{tabular}{lcccc}
\hline Change in sugar-sweetened soft drink intake & $n$ & Cases $(n)$ & $\mathrm{HR}^{*}$ & $95 \% \mathrm{Cl}$ \\
\hline Never consumers & 5026 & 267 & 1.00 & Ref. \\
Maintained low intake & 3057 & 149 & 1.03 & $0.84,1.27$ \\
Maintained high intake & 268 & 13 & 1.00 & $0.57,1.76$ \\
Increased intake & 3046 & 141 & 0.89 & $0.72,1.09$ \\
Decreased intake & 3151 & 148 & 0.93 & $0.76,1.15$ \\
\hline
\end{tabular}

Ref., reference category; SEIFA, Socio-Economic Indexes for Areas.

*Adjusted for SEIFA, country of birth and stratified by sex (due to non-proportional hazards), and adjusted for the following variables at both baseline and wave 2: alcohol intake, smoking status, physical activity, Mediterranean diet score.

intakes and those who increased or decreased intakes. A recent analysis of data from 1000 men and women of the Framingham Third Generation Cohort found that over
6 years, higher sugar-sweetened soft drink, but not artificially sweetened soft drink, consumption was associated with larger increase in visceral adipose tissue volume, but 
not with weight gain ${ }^{(16)}$. It is possible that the anthropometric measurements available in the MCCS do not capture metabolically important visceral adipose tissue. Visceral fat is associated with alterations to immunological, metabolic and endocrine function and with risk of breast, colorectal and oesophageal cancers ${ }^{(17)}$. We did not see any difference in the risk of developing an obesity-related cancer between groups with different patterns of sugarsweetened soft drink intake over time. Although the sample size was relatively small for this analysis and the number of cases per group was low, the HR did not suggest any association. It is possible that people who survived until, and attended, follow-up were somehow less susceptible to the adverse effects of sugar-sweetened soft drink consumption. Another limitation of the present analysis is that we have not included data on energy intake, which may not have differed between groups if changes in energy intake from sugar-sweetened soft drinks had been offset by intake of other foods/beverages.

The lack of association between artificially sweetened soft drinks and obesity-related cancers suggests that the observed association for sugar-sweetened soft drinks and obesity-related cancer cannot be attributed to other non-sugar components of soft drinks such as 4-methylimidazole ${ }^{(8)}$ which is considered to be possibly

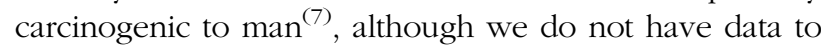
determine whether the proportion of cola-flavoured drinks including this ingredient differed between artificially sweetened soft drinks and sugar-sweetened soft drinks.

If the association of sugar-sweetened soft drinks with obesity-related cancers is not fully attributable to obesity or other non-sugar components, does that mean that sugar in the soft drinks is a problem per se? The 2007 summary of diet and cancer by the World Cancer Research Fund and the American Institute for Cancer Research concluded that there was limited evidence that foods containing sugar were associated with cancer of the colorectum and no other associations were identified ${ }^{(18)}$. Since then research from the Japanese Fukuoka case-control study has found that, after adjusting for BMI, sugar intake was positively associated with colorectal cancer only in men who smoked or did not drink alcohol ${ }^{(19)}$, and a recent casecontrol study in African-American women reported that total carbohydrate intake, apparently driven largely by sugar intake, was associated with ovarian cancer risk ${ }^{(20)}$. Both these studies hypothesised that the link was via insulin.

Added sugar rather than total sugar may be important but we cannot assess intakes of added sugar in our study. Estimates from Australian Health Survey data show that sugar-sweetened soft drinks accounted for the greatest proportion of the added sugar intake in the Australian population in 2011-12 21 . The average difference in total sugar intake between the lowest and highest consumers of sugar-sweetened soft drinks in the MCCS was $81 \mathrm{~g}$ for men and $65 \mathrm{~g}$ for women. For both sexes, this was equivalent to
3.4 servings and accounted for $74 \%$ of the difference in total sugar intake between the highest and lowest intake categories. These data suggest that soft drink consumption contributed a large proportion of the additional sugar intake in these high frequency consumers. There was no evidence of extra sugar intake according to frequency of artificially sweetened soft drink consumption, indicating that background diet was not an important contributor.

\section{Conclusion}

In conclusion, our results suggest that even for the MCCS participants who had relatively low intakes of sugarsweetened soft drinks, higher intakes were associated with increased risk of obesity-related cancers, while artificially sweetened soft drink consumption did not show the same association. We do not recommend unlimited consumption of artificially sweetened soft drinks as there is some evidence that these may be associated with obesity and cardiometabolic risk ${ }^{(14)}$. Our findings further support the Cancer Council Victoria's message to 'Rethink Sugary Drink'.

\section{Acknowledgements}

Acknowledgements: This study was made possible by the contribution of many people, including the original investigators and the diligent team who recruited the participants and who continue working on follow-up. The authors would also like to express their gratitude to the many thousands of Melbourne residents who continue to participate in the study. Cases and their vital status were ascertained through the Victorian Cancer Registry (VCR) and the Australian Institute of Health and Welfare (AIHW), including the National Death Index and the Australian Cancer Database. Financial support: Melbourne Collaborative Cohort Study (MCCS) recruitment was funded by VicHealth and Cancer Council Victoria. The MCCS was further supported by Australian National Health and Medical Research Council (grant numbers 209057, 251553 and 504711) and by infrastructure provided by Cancer Council Victoria. Conflict of interest: The authors declare they have no financial and non-financial (professional and personal) relationships with the potential to bias the work. Authorship: A.M.H., D.R.E. and J.K.B. formulated the research question, G.G.G. was responsible for designing the original cohort study and carrying out the baseline data collection, D.R.E. and G.G.G. were responsible for data collection at wave 2, J.K.B. analysed the data, A.M.H. wrote the first draft of the article and all authors contributed to the data interpretation and editing the manuscript. Ethics of buman subject participation: The MCCS was conducted according to the guidelines laid down in the Declaration of Helsinki and all procedures involving human subjects/patients were approved by the Cancer 
Council Victoria Human Research Ethics Committee. Written informed consent was obtained from all participants at baseline and wave 2 .

\section{References}

1. Australian Bureau of Statistics (2014) Australian Health Survey: Nutrition First Results-Foods and Nutrients, 2011-12. Canberra: Commonwealth of Australia.

2. Malik VS, Pan A, Willett WC \& Hu FB (2013) Sugarsweetened beverages and weight gain in children and adults: a systematic review and meta-analysis. Am J Clin Nutr 98, 1084-1102.

3. Massougbodji J, Le Bodo Y, Fratu R et al. (2014) Reviews examining sugar-sweetened beverages and body weight: correlates of their quality and conclusions. Am J Clin Nutr 99, 1096-1104.

4. Veerman JL, Sacks G, Antonopoulos N et al. (2016) The impact of a tax on sugar-sweetened beverages on health and health care costs: a modelling study. PLOS One 11, e0151460.

5. Boyle P, Koechlin A \& Autier P (2014) Sweetened carbonated beverage consumption and cancer risk: meta-analysis and review. Eur J Cancer Prev 23, 481-490.

6. World Cancer Research Fund International (2016) Obesity, physical activity and cancer, http://www.wcrf.org/sites/ default/files/Obesity-physical-activity-and-cancer-infographic. pdf (accessed September 2017).

7. International Agency for Research on Cancer (2013) 4-Methylimidazole. In IARC Monographs on the Evaluation of Carcinogenic Risks to Humans. vol. 101: Some Chemicals Present in Industrial and Consumer Products, Food and Drinking-water, pp. 447-459. Lyon: IARC.

8. Smith TJ, Wolfson JA, Jiao D et al. (2015) Caramel color in soft drinks and exposure to 4-methylimidazole: a quantitative risk assessment. PLoS One 10, e0118138.

9. Milne R, Fletcher A, MacInnis R et al. (2017) Cohort Profile: the Melbourne Collaborative Cohort Study (Health 2020). Int J Epidemiol (Epublication ahead of print version).
10. Hodge AM, Bassett JK, Shivappa N et al. (2016) Dietary inflammatory index, Mediterranean diet score, and lung cancer: a prospective study. Cancer Causes Control 27, 907-917.

11. MacInnis RJ, English DR, Hopper JL et al. (2004) Body size and composition and colon cancer risk in men. Cancer Epidemiol Biomarkers Prev 13, 553-559.

12. Rothman K, Greenland S \& Lash T (editors) (2008) Modern Epidemiology, 3rd ed. Philadelphia, PA: Lippincott Williams \& Wilkins.

13. Giles GG \& English DR (2002) The Melbourne Collaborative Cohort Study. IARC Sci Publ 156, 69-70.

14. Fowler SPG (2016) Low-calorie sweetener use and energy balance: results from experimental studies in animals, and large-scale prospective studies in humans. Physiol Behav 164, 517-523.

15. Schernhammer ES, Bertrand KA, Birmann BM et al. (2012) Consumption of artificial sweetener- and sugar-containing soda and risk of lymphoma and leukemia in men and women. Am J Clin Nutr 96, 1419-1428.

16. Ma J, McKeown NM, Hwang SJ et al. (2016) Sugarsweetened beverage consumption is associated with change of visceral adipose tissue over 6 years of follow-up. Circulation 133, 370-377.

17. Doyle SL, Donohoe CL, Lysaght J et al. (2012) Visceral obesity, metabolic syndrome, insulin resistance and cancer. Proc Nutr Soc 71, 181-189.

18. World Cancer Research Fund \& American Institute for Cancer Research (2007) Food, Nutrition, Physical Activity, and the Prevention of Cancer: A Global Perspective. Washington, DC: American Institute for Cancer Research.

19. Wang Z, Uchida K, Ohnaka K et al. (2014) Sugars, sucrose and colorectal cancer risk: the Fukuoka colorectal cancer study. Scand J Gastroenterol 49, 581-588.

20. Qin B, Moorman PG, Alberg AJ et al. (2016) Dietary carbohydrate intake, glycaemic load, glycaemic index and ovarian cancer risk in African-American women. BrJ Nutr 115, 694-702.

21. Lei L, Rangan A, Flood VM et al. (2016) Dietary intake and food sources of added sugar in the Australian population. Br J Nutr 115, 868-877. 